\title{
SALOMÓN USQUE: UNA APOSTILLA A LA TRADUCCIÓN DEL CANZONIERE DE PETRARCA
}

$\mathrm{Al}$ estudio de las traducciones de antaño es inherente "el cotejo escrupuloso de un crecido número de traducciones con sus originales". 1 Extendido a un amplio número de obras, dicho análisis permite profundizar nuestro conocimiento de la teoría de la traducción en siglos pasados, estudiar el complejo proceso de trasvase del texto a otro ambiente cultural y lingüístico, así como adentrarnos, a través del quehacer del lector-intérpretetraductor, en la recepción y difusión de los textos de los autores clásicos.

1.

Hasta la fecha han sido escasamente abordadas las traducciones castellanas del Canzoniere (C) de Petrarca en la segunda mitad del siglo XVI ${ }^{2}$, las cuales citamos en orden cronológico: De los sonetos, canciones, mandriales y sextinas del gran poeta y orador Francisco Petrarca, traducción parcial de Salomón Usque, [seud. Salusque Lusitano], Venecia, 1567 (SU); Los sonetos y canciones del poeta Francisco Petrarca, traducción Enrique Garcés, Madrid, 1591; y la de Francisco Trenado y Ayllón que, aunque dispuesta para la imprenta a fines de 1598 , nunca llegó a publicarse. ${ }^{3}$

1 Cit. de Peter Russell, Traducciones y traductores en la Península Ibérica (1400-1550), Barcelona, 1985, p. 7, donde se establece como modelo a seguir el pormenorizado análisis de Margherita Morreale, Castiglione $y$ Boscán: el ideal cortesano en el renacimiento español, Madrid, BRAE, 1959, sobre la versión castellana del Cortegiano de Baldassare Castiglione llevada a cabo por Juan Boscán (Barcelona, 1534). De la misma autora citamos "Apuntes para la historia de la traducción en la Edad Media", «Revista de Literatura», 15 (1959), 1-8; "Los cabos sueltos en el estudio de las traducciones de textos de antaño" en: Actas de las jornadas de estudio suizo-italianas de Lugano (22-23 de febrero 1980), Milán, 1981, 171-173. V. q. Gianfranco Folena, "«Volgarizzare» e «tradurre»: Idea e terminologia della traduzione dal Medio Evo italiano e romanzo all'Umanesimo Europeo" en: La traduzione. Saggi e Studi, Trieste, 1973, 57-120, ahora ampliado y con la bibliografia puesta al día en Volgarizzare e tradurre, Torino, 1991.

2 Vid. Franco Meregalli, "Sulle prime traduzioni spagnole di sonetti del Petrarca" en: Traduzione e tradizione europea del Petrarca, Padua, 1975, 55-63, y Maria Pilar Manero Sorolla, "Las traducciones castellanas quinientistas de la obra de Petrarca" en: Introducción al estudio del petrarquismo en España, Barcelona 1987, 152-159.

3 Esta es la noticia escueta que proporcionan Meregalli y Manero, citando a Palau y Dulcet, Manual del librero hispanoamericano, Barcelona, 1948, s.v. Petrarca. Para mayores detalles sobre esta traducción hoy perdida vid. prólogo de Francisco Trenado de Ayllón a su Arte muy curiosa por la qual se enseña muy de rayz el entender y hablar la Lengua Italiana, Medina del Campo, 1596, donde en fol. 12 el autor precisa: "lo demás de aquella lengua , como son vocablos, acento y pronunciación lo podrá sacar el lector del texto con la práctica y lección del Petrarcha, y de la traducción que yo hago en Castellano correspondiente al dicho texto, que por este respecto de industria y con mucho acuerdo hize la traducción literal, por no quitar de su asiento á la trabazon y eslabonamiento de los epítetos del dicho autor, que con tanto artificio están cada palabra en su lugar, y no sólo las 
De ellas sólo SU ha merecido una mínima atención por parte de María Pilar Manero Sorolla ${ }^{4}$, y aun en este caso la investigadora se ha ceñido a la divulgación de los escasos datos biográficos a nuestro alcance sobre el traductor, a la descripción tipográfica de la edición veneciana y al comentario del prólogo de Alonso de Ulloa que incluye importantes consideraciones sobre el quehacer de Salomón Usque.

El acercamiento de Manero, basado en aspectos externos al texto, le llevaba a concluir que el traductor se sirvió de la difundida edición de Canzoniere con el comentario de Alessandro Vellutello (Venecia, 1525). Partía para ello de la evidencia de que la traducción parcial de Salomón Usque refleja la primera parte de la edición de Vellutello ${ }^{5}$, con idéntica ordenación de los sonetos y canciones del poeta toscano.

2.

Un estudio más minucioso de esta versión pone de relieve algunas características que nos hacen suponer un acceso más complejo del traductor a la obra de Petrarca.

Es innegable que Salomón Usque, judío portugués afincado en Ferrara ${ }^{6}$, tuvo a su alcance una de las ediciones de Canzoniere con el comentario de Vellutello. Este no pudo ser sin embargo la única edición de referencia. La "Vida y costumbres del poeta"7, un preámbulo que se encuentra en casi todas las ediciones petrarquistas del siglo XVI, delata numerosas diferencias con respecto al texto que figuraba en las ediciones de Vellutello a partir de 1525. Sigue en cambio al pie de la letra el capítulo preliminar que figuró a partir

palabras, mas aun las sílabas: y por esta razón no quise usar en la traslación destas rimas de la libertad de la poesía Castellana; porque fuera en mucho agravio de la armonía de la poesía del Petrarcha, y por seguir el modo que el Maestro Nebrixa tubo en su Gramática, tan recibida, y con razón, en toda España". Años más tarde, en una carta de 1599 a D. Diego Sarmiento de Acuña, corregidor de Toro, Trenado lamenta que no haya llegado a publicarse la mencionada traducción: "enviara también (si estuvieran impressas) las Rimas del Petrarca que yo tanto deseo verlas en tal término, sin moverme más interes de desear que semejantes ingenios como el de V.m. gozaran de la alteza de aquellas rimas, porque verdaderamente es un nuevo y esquisito manjar del alma; pero mi desgracia y no el mucho merecimiento dellas, es causa que los tiempos que corren estén tan inclinados al interés, que no hagan caso de otra cosa alguna que no se le acarreare" (citamos de Cristóbal Pérez Pastor, La imprenta en Medina del Campo, Madrid, 1895, pp. 309-310).

4 “La primera traducción de las Rime de Petrarca en lengua castellana" en: Homenaje al profesor Antonio Vilanova, Barcelona, 1989, 377-391 (con una exhaustiva información bibliográfica).

5 Es conocida la ingeniosa ordenación en tres partes propuesta por Vellutello, separando los poemas en vida y en muerte de Laura, y relegando a un apartado final aquellos que el comentarista juzga ajenos a dicho tema. Vid. Ernest Hatch Wilkins, "The Separation of Canzoni and Sonnets in Petrarchan Manuscripts and Editions" en: Tha Making of the "Canzoniere", and Other Petrarchan Studies, Roma, 1951, 265-274. La edición con las anotaciones de Girolamo Ruscelli (Venecia, Plinio Pietrasanta, 1554) testimonia la fortuna de dicha tripartición, tal como el humanista confiesa en su preliminar a los lectores: "Et in quanto all'ordine habbiamo seguito, come cominciai a dir di sopra, quello del Vellutello".

6 Sobre la activa comunidad judía sefardita en la Ferrara de estos años vid. Pier Cesare Ioly Zorattini, "Ebrei sefarditi e marrani a Ferrara dalla fine del Quattrocento alla devoluzione del Ducato estense" en: Libri, idee $e$ sentimenti religiosi nel Cinquecento italiano, Modena, 1987, 117-130, y Margherita Morreale, "La Bibbia di Ferrara 450 anni dopo la sua pubblicazione" en: Atti della Accademia Nazionale dei Lincei. Memorie, Serie IX, vol. 4, fascicolo 3, Roma, 1994, 173-233.

7 Pp. ix-xii. 
de la segunda edición de la poesía en vulgar de Petrarca con el comentario de Bernardino Daniello: Sonetti, canzoni e triomphi (Venezia, 1549). ${ }^{8}$

La nota biográfica no puede ser de por sí un elemento probatorio de la(s) edicion(es) que pudo haber manejado Salomón Usque, ya que dicho capítulo podría haber sido traducido en una segunda fase a instancias del impresor veneciano Nicolò Bevilacqua. Sin embargo un examen atento de la versión castellana de Salomón Usque revela una familiaridad con el comentario de Daniello.

Es sabido que el humanista de Lucca, siguiendo el ejemplo de Pietro Bembo para la edición aldina (Venecia, 1501), en la que se incorporaron variantes transcritas de un manuscrito "di mano medesima del poeta", según informa el editor en el colofón, agrupó en un preámbulo lecciones que Daniello vinculaba a fases intermedias de composición de las rimas. ${ }^{9}$ Variantes que en algunos casos fueron preferidas por Salomón Usque llegado el momento de verter Canzoniere al castellano. Tal consideración se desprende del siguiente cotejo de versos:

\section{Bembo}

(Venecia, 1501)

C 23.96:

$\mathrm{Ne}$ tacendo potea di sua man trarlo

C 23.121:

L'alma; ch'è sol da

Dio fatta gentile

C 23.160:

Et anchor de miei can fuggo lo stormo
Vellutello

(Venecia, 1525)

Ne tacendo potea di

sua man trarlo

L'alma; ch'è sol da

Dio fatta gentile

Et anchor de miei

can fuggo lo stormo
Daniello

(Venecia, 1549)

Ne tacendo potea

da lei scamparlo

L'anima che è da

Dio fatta gentile

E de miei propri

can fuggo lo stormo
Usque

(Venecia, 1567

$\mathrm{Ni}$ callando podia

d'ella librallo

El alma, que es de

Dios hecha divina ${ }^{10}$

Y de mis propios

canes fuir quiero

8 SU recurre ocasionalmente al comentario de Vellutello para la redacción del preámbulo: la coronación del poeta en el Campidoglio de Roma; la noticia de la muerte de Laura y el viaje a Aviñon; el regreso a Italia y el afincamiento en Milán y Padua; la embajada de Boccaccio; la muerte del poeta. Sigue siendo de utilidad la consulta de A. Solerti, Storia Letteraria d'Italia: Le vite di Dante, Petrarca e Boccaccio scritte fino al secolo decimosesto, Milano, 1904, 237-668.

9 Atañen a cuatro canciones y diecisiete sonetos: C 23 [SU canc. 12], 46 [son. 23], 123 [son. 187], 150 [son. 82], 152 [son. 104], 154 [son. 85], 155 [son. 86], 159 [son. 91 ] , 188 [son. 158], 192 [son. 115], 193 [son. 116], 194 [son. 154], 196 [son. 161], 197 [son. 120], 199 [son. 73], 211 [son. 172], 268, 270, 297, 319, 323. Si exceptuamos C 23 [canc. 12] no hallamos rastro de las variantes señaladas por Daniello en la versión castellana de estos poemas (salvo, quizás, el uso de la perífrasis ir + ger. en C 196.2 [son. 161] "Va murmurando" $\leftarrow$ "Va mormorando").

${ }^{10}$ La posición en rima determina la equivalencia divino $\leftarrow$ gentil (Daniello: "nobile e virtuosa"), si bien podría ser sintomática de la confesión religiosa del traductor, para el que pudiera prevalecer la ac. gentil: "no judío' (cfr. C 71.11 [SU canc. 3] "Ha del sugeto un habito gracioso" $\leftarrow$ "tien dal soggeto un habito gentile"; C 71.25 "vuestro desdén estrago" $\leftarrow$ "vostro gentile sdegno"; pero C 127.37 [canc. 11] "dond'oy alberga l'anima gentil" $\leftarrow$ "dove oggi alberga l' anima gentile"). Procede de modo inverso en C 72.1 [canc. 4] "Gentil mi Diosa" $\leftarrow$ "Gentil mia donna", donde la presencia del adj. hace aflorar el léxico religioso, si bien el sust. diosa (y no Dios) no impide la construcción del sintagma. 
3.

El cotejo de C 23 entre la traducción de Salomón Usque y el original italiano delata una coincidencia formal con algunas de las variantes apuntadas por Daniello, a su vez derivadas de manuscritos autógrafos de Petrarca. La interacción de las ediciones de Canzoniere comentadas por Vellutello y por Daniello nos permiten atisbar la intensa difusión de la poesía en vulgar del poeta toscano en los ambientes humanistas de Ferrara en los que se enmarca la labor de Salomón Usque.

\section{Nota Bibliográfica}

Las citas se hacen en orden a las siguientes ediciones:

- Le cose volgari di Messer Francesco Petrarcha [corr. Pietro Bembo], Vinegia, Aldo Romano [Aldo Manuzio il Vecchio], 1501.

- Le volgari opere del Petrarcha con la espositione di Alessandro Vellutello da Lucca, Vinegia, Giovanniantonio [et] Fratelli da Sabio, 1525.

- Sonetti, canzoni e triomphi di M. Francesco Petrarca, con la spositione di Bernardino

Daniello da Lucca, Vinegia, Pietro [et] Gioanmaria Fratelli de Nicolini da Sabio, 1549.

- De los sonetos, canciones, mandriales y sextinas del gran poeta y orador Francisco

Petrarca. Traduzidos de Toscano por Salusque Lusitano. Parte primera, Venecia, Nicolao Bevilaqua, 1567.

Agradecemos a la dirección y al personal de la "Biblioteca Attilio Hortis" de Trieste las facilidades que nos han concedido para la consulta del Fondo Rossettiano.

\section{Povzetek}

\section{SALOMÓN USQUE:}

\section{POSTILA K PREVODU PETRARKOVEGA "KANCONIERA"}

Prispevek naj bi omogočil boljše poznavanje dela Salomona Usqueja, ki je leta 1567 v Benetkah objavil španski prevod prvega dela Petrarkovega Kanconiera.

Ugotavlja se, da dolguje prevod $v$ španščino marsikaj izdajam toskanskega pesni$\mathrm{ka}$ in komentarjem Alessandra Vellutella in predvsem Bernardina Daniella iz Lucche. Opombe le-tega, v uvodu k drugi izdaji Kanconiera iz leta 1549, so opazne zlasti v variantah 23. kancone.

Izbrana bibliografija ( $v$ opombah) skuša biti vabilo $\mathrm{k}$ študiju prevodov klasičnih del v španski renesansi. 